\title{
Increasing Oxygen Mass Fraction in Blind Headings of a Plateau Metal Mine by Oxygen Supply Duct Design: A CFD Modelling Approach
}

\author{
Zijun Li $\mathbb{D}^{D}$, Shuqi Zhao $\left(\mathbb{D}\right.$, Rongrong Li $\mathbb{D}^{D}$, Yilong Huang, Yu Xu, and Pinfang Song \\ School of Resources and Safety Engineering, Central South University, Changsha 410083, China \\ Correspondence should be addressed to Zijun Li; anquan@csu.edu.cn
}

Received 12 December 2019; Accepted 14 February 2020; Published 4 May 2020

Academic Editor: Fausto Arpino

Copyright ( 2020 Zijun Li et al. This is an open access article distributed under the Creative Commons Attribution License, which permits unrestricted use, distribution, and reproduction in any medium, provided the original work is properly cited.

\begin{abstract}
Hypoxia problem has always been a difficult point in plateau tunneling projects. To solve this problem, a blind heading face in a plateau metal mine in western China was taken as the physical model, and the computational fluid dynamics was used to analyze the oxygen mass fraction distribution and oxygen-increasing effect in $1 \mathrm{~m}, 3 \mathrm{~m}$, and $5 \mathrm{~m}$ roadway sections from the heading face. The optimal ventilation system was first built to obtain the optimum height and length of the airflow ducts. Then different cases with various oxygen supply duct designs were built in 2 scenarios. The results found that different oxygen supply duct design has significant influence on the oxygen distribution in the heading face. Also, each design has different optimal height of oxygen outlet. The oxygen supply effect is best when some small holes are made in the oxygen supply duct to diffuse oxygen to the working surface. The finding of this paper is helpful for effective and economical oxygen supply in roadway excavation of plateau metal mine and tunnel.
\end{abstract}

\section{Introduction}

Western China is a crucial strategic reserve base in metal mineral resources [1]. However, due to the adverse natural environment such as low pressure and subpar oxygen concentration caused by high altitude, the technical requirements and difficulties of plateau mine mining are high, and the construction is also very difficult. Therefore, the miners and mechanical equipment there are severely tested. On the one hand, due to the high altitude, the oxygen partial pressure in the air decreases. As a result, the miners will suffer from hypoxia and their labor force will decline significantly. Hypoxia exposure negatively impacts cognitive performance and mood, such as increasing anxiety, anger, and fatigue and lower rates of positive mood and vigor $[2,3]$. The differences between plateaus and plains also have adverse physiological reactions on miners $[4,5]$. Their physiological workload is equivalent to that of heavy manual labor in a plain environment, even when they do what appears to be low-intensity physical labor $[6,7]$. On the other hand, the engine power, traction characteristics, acceleration, and slope climbing performance of machinery constructed in high-altitude heading face are reduced dramatically. Thus, hypoxia has been a crucial concern in the plateau metal mine.

Traditionally, in mine ventilation, researchers mainly focus on ventilation system optimization [8-11], dust and harmful gas flow and diffusion pattern [12-14], and thermal environment [15-17] in underground mining. Usually, in situ measurement, laboratory experiment, and numerical simulation methods were used in their research [15]. However, there are few researches on increasing oxygen with ventilation in high altitude roadway driving worldwide due to the geography and policy. Most of the research in this field was done in China. University of Science and Technology Beijing has done a series of works to study the anoxic problem in plateau metal mine. For example, by means of numerical simulation, Zhong et al. [18] obtained the parameters of ventilation and oxygen supply and roughly determined the optimized position of the duct layout. Wang [19] studied the hypobaric hypoxia underground work environment in plateau areas and then 
established the corresponding formula of altitude, oxygen saturation, and labor load through the research on human endurance physiological indices. Some researchers in Southwest Jiaotong University [7, 20, 21] explored the effectiveness of individual oxygen-supply systems and diffused oxygen supply systems considering migrants' physical and psychological reactions in Balang Mountain Tunnel at an altitude of $3854 \mathrm{~m}$ in winter. The results indicated that selecting a proper oxygen-supply system for different tunnel construction procedures requires taking the features of the various systems into consideration for migrants moving from the plains to a highaltitude area.

In general, two methods were used in increasing oxygen mass fraction in the heading face in previous research: one is oxygen supply, and the other is pressurized ventilation. The equipment required for pressurization and ventilation is complex and the effect of oxygenation is not obvious, so the application range is not wide. Most of the research on oxygen supply was focused on the rough design of ventilation duct location. In brief, few researches have been done to focus on the design and layout of oxygen duct in increasing oxygen with ventilation in plateau metal mines. For this reason, a study on increasing oxygen concentration in blind heading of a plateau metal mine by optimizing oxygen supply duct location is needed.

The aim of this study is to provide an optimized technical solution for increasing oxygen mass fraction of plateau metal mines. The CFD model was built based on Pulang copper mine, China. Firstly, the design models and boundary conditions were determined based on the actual conditions of the roadway environment of Pulang copper mine. Then a series of preliminary works have been done to determine the optimal location of forcing duct, including the distance between the forcing duct and the blind heading face and the height of the forcing duct center from the ground in roadway. After that, two selected geometry types with different oxygen supply duct design were built and compared to determine the most economical and efficient one. Finally, some other oxygen supply duct designs were simulated and further discussed. The optimizing auxiliary ventilation system and oxygen supply duct design were suggested. This mathematical method can be applied to underground mining of noncoal mines.

\section{Model Description}

There are three types of auxiliary ventilation systems: forcing ventilation (FV), exhausting ventilation (EV), and mixed ventilation (MV). The air is thin at high altitudes, so pure FV or EV is not suitable for blind headings in plateau metal mines, which require a large amount of air to discharge smoke and dust. Single FV will lead to a wide range of smoke diffusion and spread in the roadway along with the airflow. Therefore, it has relatively low dust removal effect and poor environment of low pressure and low oxygen concentration on the plateau. MV is more suitable for ventilation at high altitude; it can increase air density, keep the system in a positive pressure state, and contribute to pollution discharge. So, the far-forcing-near-exhausting mixed ventilation is used in this study.

2.1. Geometry Model. A computational 3D three-centered $2.8 \mathrm{~m}$ wide, $2.6 \mathrm{~m}$ high, and $30 \mathrm{~m}$ long arch (total crosssectional area: $S_{0}=6.8720 \mathrm{~m}^{2}$ ) roadway model was built by ANSYS FLUENT module based on the physical conditions of a one ended roadway of Pulang copper, a plateau mine in Yunnan, China, as shown in Figure 1.

2.2. Meshing. The reasonable design and high-quality generation of mesh are the preconditions of CFD (computational fluid dynamics) calculation. The mesh size has a great influence on the accuracy of numerical simulation, so it is necessary to do mesh independence test. The details of mesh such as relevance, size function, and growth rate were set to different values. After that, three meshes with different amount of elements, $2.88 \times 10^{6}, 3.17 \times 10^{6}$, and $3.71 \times 10^{6}$, were generated. Figure 2 shows the distribution of airflow velocity at the position of $X=0 \mathrm{~m}$ and $Y=1.3 \mathrm{~m}$, along the roadway with these three meshes. It can be found that the airflow velocity of $3.17 \times 10^{6}$ elements is stable between the other two meshes. Therefore, the mesh with $3.17 \times 10^{6}$ elements was more suitable, and it is chosen for the numerical simulation.

The quality of the mesh includes the flattening degree of all the mesh nodes, which is generally judged by skewness and aspect ratio. In accordance with previous experience, the skewness of triangular and tetrahedral mesh should not be greater than 0.95 , and the average should not be greater than 0.33 . Also, the aspect ratio of the core of airflow should be kept at 1, while for the boundary layer mesh, it should not be lower than 0.05 [22]. The detailed values of skewness and aspect ratio are shown in Table 1. The maximal skewness is lower than 0.95 and the aspect ratio is also in a fine range, suggesting that a high-quality mesh has been generated.

2.3. RNG $k-\varepsilon$ Model. The mixed ventilation of blind-head roadway is actually a limited attached jet with limited space. The assumptions of the mathematical model are as follows.

Assume that the ventilated air flow can be regarded as an incompressible fluid, and the dissipative heat caused by the viscous force of the fluid can be ignored; also, the wall insulation and isothermal ventilation can be ignored.

Assume that the flow field has a high turbulent Reynolds value, at which time the turbulent viscosity of the fluid is isotropic, and the turbulent viscosity coefficient can be taken as a scalar.

On the basis of assumptions, the ventilation flow in blind-head roadway can be represented by the $R N G k$ - $\varepsilon$ model.

The $R N G \quad k-\varepsilon$ model was derived using a statistical technique called renormalization group theory. It is similar in form to the standard $k-\varepsilon$ model but includes the following refinements: 


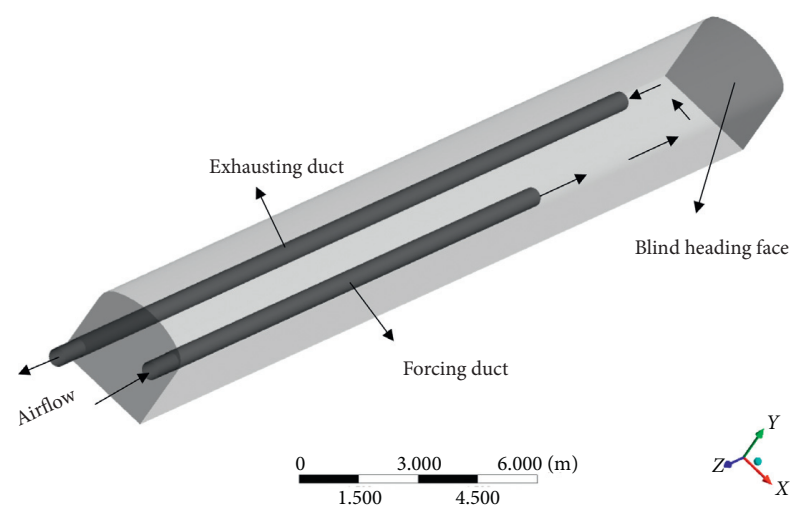

FIGURE 1: Geometry model of roadway ventilation system.

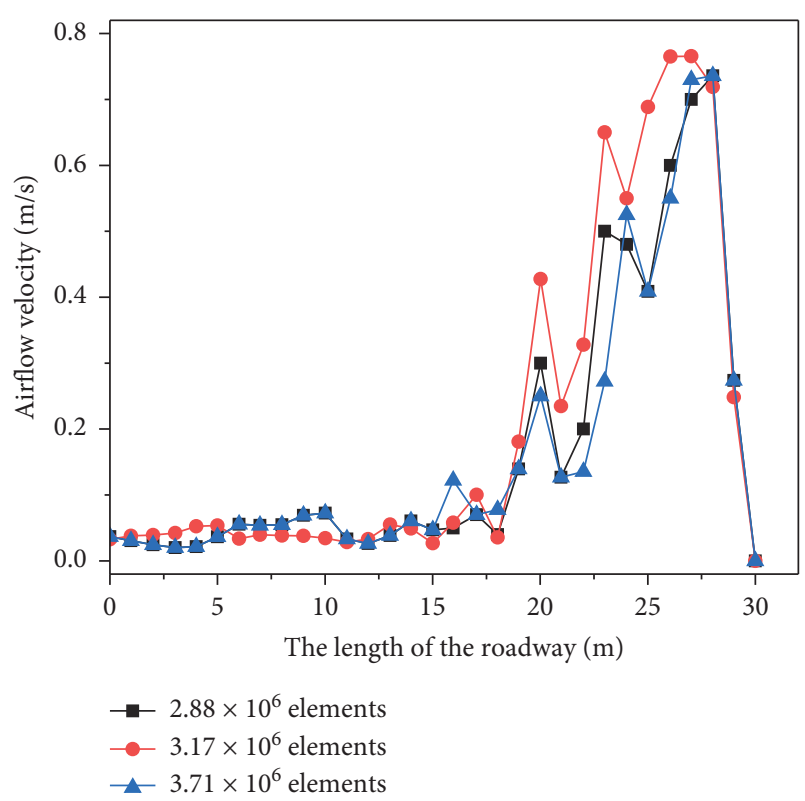

Figure 2: Airflow velocity along the roadway with three meshes.

TABLE 1: The skewness and orthogonal quality of roadway model mesh.

\begin{tabular}{lcccc}
\hline & Min & Max & Average & $\begin{array}{c}\text { Standard } \\
\text { deviation }\end{array}$ \\
\hline Skewness & $1.56 \times 10^{-4}$ & 0.8987 & 0.2151 & 0.1286 \\
Aspect ratio & 1.1629 & 1313.8000 & 14.0310 & 70.1170 \\
\hline
\end{tabular}

(a) The RNG model has an additional term in its equation that improves the accuracy for rapidly strained flows.

(b) The effect of swirl on turbulence is included in the $R N G$ model, enhancing the accuracy for swirling flows.

(c) The $R N G$ theory provides an analytical formula for turbulent Prandtl numbers, while the standard $k-\varepsilon$ model uses user-specified constant values. (d) While the standard $k$ - $\varepsilon$ model is a high-Reynolds number model, the RNG theory provides an analytically derived differential formula for effective viscosity that accounts for low-Reynolds number effects. Effective use of this feature does, however, depend on an appropriate treatment of the near-wall region.

The transport equations for the $R N G k-\varepsilon$ model have a similar form to the standard $k-\varepsilon$ model, as shown in equations (1) and (2).

$$
\begin{aligned}
\frac{\partial}{\partial t}(\rho k)+\frac{\partial}{\partial x_{i}}\left(\rho k \mu_{j}\right)= & \frac{\partial}{\partial x_{j}}\left(\alpha_{k} \mu_{\mathrm{eff}} \frac{\partial k}{\partial x_{j}}\right)+G_{k}+G_{b} \\
& -\rho \varepsilon-Y_{M}+S_{k} \\
\frac{\partial}{\partial t}(\rho \varepsilon)+\frac{\partial}{\partial x_{i}}\left(\rho \varepsilon \mu_{i}\right)= & \frac{\partial}{\partial x_{j}}\left(\alpha_{k} \mu_{\mathrm{eff}} \frac{\partial \varepsilon}{\partial x_{j}}\right)+C_{1 \varepsilon} \frac{\varepsilon}{k}\left(G_{k}+C_{3 \varepsilon} G_{b}\right) \\
& -C_{2 \varepsilon} \rho \frac{\varepsilon^{2}}{k}-R_{\varepsilon}+S_{\varepsilon},
\end{aligned}
$$

where $G_{k}$ represents the generation of turbulence kinetic energy due to the mean velocity gradients. $G_{b}$ is the generation of turbulence kinetic energy due to buoyancy. $Y_{M}$ represents the contribution of the fluctuating dilatation in compressible turbulence to the overall dissipation rate. $C_{1 \varepsilon}$, $C_{2 \varepsilon}$, and $C_{3 \varepsilon}$ are constants; generally, $C_{1 \varepsilon}=1.44$ and $C_{2 \varepsilon}=1.92$. The quantities $\alpha_{k}$ and $\alpha_{\varepsilon}$ are the inverse effective Prandtl numbers for $k$ and $\varepsilon$, respectively, and $S_{\varepsilon}$ are userdefined source terms.

\subsection{Boundary Conditions}

2.4.1. Pressure and Temperature. Pulang copper mine is $3,400 \mathrm{~m}$ to $4,500 \mathrm{~m}$ above sea level, and 3,400 $\mathrm{m}$ was taken in this simulation to calculate the atmospheric pressure based on empirical equation (3):

$$
P_{H}=101.325 \times\left(1-\frac{z}{44329}\right)^{5.255876},
$$

where $H$ is the height above sea level and $P_{H}$ is the corresponding atmospheric pressure.

It can be calculated from equation (3) that the atmospheric pressure at $3,400 \mathrm{~m}$ above sea level is $66.6139 \mathrm{Kpa}$.

The mining area belongs to the subtropical mountain monsoon climate, with annual mean temperature around $4^{\circ} \mathrm{C}(277.15 \mathrm{~K})$, average summer temperature around $15^{\circ} \mathrm{C}$ $(288.15 \mathrm{~K})$, and average winter temperature around $-5^{\circ} \mathrm{C}(268.15 \mathrm{~K})$. The average summer temperature $(288.15 \mathrm{~K})$ was used in the simulation.

2.4.2. Ventilation Volume Airflow and Velocity. In the process of mine driving, the miners work after a large amount of blasting smoke is discharged. Therefore, the ventilation volume airflow and oxygen supply of the heading face are not determined by the way of removing blasting 
smoke but only according to the minimum dust exhaust air volume [23], as shown in equation (4).

$$
Q_{0}=v_{0} \times S_{0} \text {, }
$$

where $Q_{0}$ is the volume airflow, $\mathrm{m}^{3} / \mathrm{s}$; it is also the volume airflow of forcing duct; $v_{0}$ is the minimum dust removal velocity, $0.15 \mathrm{~m} / \mathrm{s}$, in rock roadway; $S_{0}$ is the total crosssectional area (CSA) of the roadway (blind heading face), $\mathrm{m}^{2}$.

According to equation (4), the volume airflow of forcing duct is $1.0308 \mathrm{~m}^{3} / \mathrm{s}$. The diameter of forcing duct and exhausting duct is $0.5 \mathrm{~m}$ (CSA: $\left.S_{1}=S_{2}=0.1963 \mathrm{~m}^{2}\right)$, so the airflow velocity of forcing duct can be determined as $5.25 \mathrm{~m} /$ s. 0.8 was taken as extraction ratio of mixed ventilation, so the volume airflow and velocity of the exhausting duct can be determined, as shown in Table 2.

2.4.3. Oxygen Supply Velocity. Set the oxygen mass percentage increase to $5 \%$ as the target oxygen-increasing effect under different cases, so the oxygen content at the altitude of $3,400 \mathrm{~m}$ can reach the oxygen level of the plain. The mass fraction and volume fraction of oxygen in the air are 0.2319 and 0.2090 , respectively. After a relative increase of $5 \%$, the mass fraction and volume fraction of oxygen are 0.2435 and 0.2198 , respectively. So the oxygen supply velocity can be calculated based on equations (5) and (6).

$$
\begin{aligned}
\varphi_{o_{2}} & =\frac{Q_{3}+Q_{1} \times 0.2090-Q_{2} \times 0.2198}{Q_{1}+Q_{3}-Q_{2}} \\
v_{3} & =\frac{Q_{3}}{S_{3}}
\end{aligned}
$$

where $\psi_{02}$ is volume fraction of oxygen after a relative increase of $5 \% ; Q_{3}$ is the oxygen supply ration, $\mathrm{m}^{3} / \mathrm{s} ; Q_{3}$ is oxygen supply velocity, $\mathrm{m} / \mathrm{s} ; S_{3}$ is the cross-sectional area of oxygen supply duct, $m_{2}$. The diameter of oxygen supply duct is $0.05 \mathrm{~m}\left(S_{3}=0.0020 \mathrm{~m}^{2}\right)$, so the oxygen supply velocity was determined as $4.36 \mathrm{~m} / \mathrm{s}$, as shown in Table 2 .

2.4.4. Roughness. To model the wall roughness effects, two roughness parameters must be specified: roughness height, $K_{s}$, and roughness constant, $C_{s}$. The default roughness height is zero, which corresponds to smooth walls. For a uniform sand-grain roughness, the height of the sand grain can simply be taken from $K_{s}$. For a nonuniform sand grain, however, the mean diameter $\left(D_{50}\right)$ would be a more meaningful roughness height. For other types of roughness, an "equivalent" sand-grain roughness height could be used for $K_{s}$. The above approaches are only relevant if the height is considered constant per surface. Choosing a proper roughness constant $\left(C_{s}\right)$ is dictated mainly by the type of the given roughness. The default roughness constant $\left(C_{s}=0.5\right)$ was determined so that, when used with $k-\varepsilon$ turbulence models, it reproduces Nikuradse's resistance data for pipes roughened with tightly packed, uniform sand-grain roughness. For instance, there is some experimental evidence that, for nonuniform sand-grain, ribs, and wire-mesh roughness, a higher value $\left(C_{s}=0.5-1.0\right)$ is more appropriate. For the roughness of the roadway in this paper, the roughness height $\left(K_{s}\right)$ was set to 0.03 , and the roughness constant $\left(C_{s}\right)$ was set to 0.6 .

2.5. Preliminary Work. Based on the research findings, the constraint conditions for the distance between the ventilation ducts and the blind heading face can be written as equations (7) and (8).

$$
\begin{aligned}
& Z_{f} \geq(4 \sim 5) \sqrt{S_{0}} \\
& Z_{e} \leq 1.5 \sqrt{S_{0}}
\end{aligned}
$$

where $Z_{f}$ is the distance between the forcing duct and the blind heading face; $Z_{e}$ is the distance between the center of the exhausting duct and the blind heading face.

A series of preliminary works have been done to determine the optimal distance between the forcing duct $\left(Z_{f}\right)$ and the blind heading face and the height of the center of the forcing duct from the ground $\left(H_{f}\right)$ in roadway. In this part, the exhausting duct is put on the ground and $3 \mathrm{~m}$ away from the blind heading face based on equation (6). The center of oxygen supply duct is $1.60 \mathrm{~m}$ away from the ground. Other variable settings are shown in Table 3.

The optimal case can be selected in these four cases comparison of the best oxygen mass fraction distribution in the plane, which is $3 \mathrm{~m}$ away from the blind heading face, and the result is shown in Figure 3.

The breathing zone is the height range of the zone where the miners breathe when working; $1.2 \mathrm{~m}$ to $1.6 \mathrm{~m}$ above the ground was taken as breathing zone in this paper. As shown in Figure 3, when the forcing duct is under the oxygen supply duct (case 1.1 and case 1.3), oxygen is concentrated in the upper part of the roadway about $2 \mathrm{~m}$ above the ground due to the relatively high pressure caused by airflow blowing out from the forcing duct. The oxygen concentration in the breathing zone $(1.2 \mathrm{~m}-1.6 \mathrm{~m})$ did not increase significantly, so it is a waste of oxygen. By comparing case 1.1 , case 1.2 , case 1.3 , and case 1.4 , it can be found that the oxygen mass fraction is higher when the forcing duct is $12 \mathrm{~m}$ away from the blind heading face than when it is $14 \mathrm{~m}$ away. Obviously, case 1.2 presents the optimal result in the four comparisons, so it was applied in the following work.

\section{Dispersion Oxygen Supply Duct Designs}

The heading face is the main working area of roadway excavation. However, the heading face is in the dead corner of airflow ventilation with poor ventilation effect. Due to the consumption of oxygen by blasting, equipment, and personnel, the oxygen concentration in this area is lower than other places in roadway. Only by transporting oxygen to this area can the problem of hypoxia of the miners be solved effectively. The method that transports oxygen directly to the heading face and makes it diffusely distributed is called diffusion oxygen supply. With plenty of high-altitude tunnels and mines, this method has been successfully 
TABLE 2: The parameters of ventilation duct and oxygen supply duct.

\begin{tabular}{lccc}
\hline & Duct diameter $(\mathrm{m})$ & Volume airflow $\left(\mathrm{m}^{3} / \mathrm{s}\right)$ & Airflow velocity $(\mathrm{m} / \mathrm{s})$ \\
\hline Forcing duct & $D_{1}=0.50$ & $Q_{1}=1.0308$ & $v_{1}=5.25$ \\
Exhausting duct & $D_{2}=0.50$ & $Q_{2}=0.8246$ & $v_{2}=4.20$ \\
Oxygen supply duct & $D_{3}=0.05$ & $Q_{3}=0.0084$ & $v_{3}=4.20$ \\
\hline
\end{tabular}

TABLE 3: Specific settings in the four cases.

\begin{tabular}{lcc}
\hline & $Z_{f}(\mathrm{~m})$ & $H_{f}(\mathrm{~m})$ \\
\hline Case 1.1 & 12.00 & 1.25 \\
Case 1.2 & 12.00 & 1.95 \\
Case 1.3 & 14.00 & 1.25 \\
Case 1.4 & 14.00 & 1.95 \\
\hline
\end{tabular}

applied in the technique of increasing oxygen in the heading face of plateau mines and tunnels in China. For the first time, Yan et al. [21] carried out field test on the dispersive oxygen supply and obtained the variation rule of oxygen concentration in the roadway. The results show that the diffusion oxygen supply is effective in improving oxygen concentration and human body function. Liu et al. [24] developed a device that is distributed symmetrically on both sides of the heading face and makes the oxygen spray out in the form of jet atomization and forms an oxygen diffusion barrier. The combination of diffusion oxygen supply and oxygen bar car was also put forward to ensure the oxygen supply to miners.

3.1. Scenario 1: Vertical and Horizontal Oxygen Outlet. Besides the fact that the distance from the airflow duct to the heading face is related to the oxygen concentration distribution, the position and design of the oxygen supply duct itself are also closely related to the oxygen concentration distribution in diffusion oxygen supply. In this part, two geometry types with vertical and horizontal oxygen outlet direction were built, as shown in Figures 4 and 5 .

The height of oxygen duct outlet was set to $1.7 \mathrm{~m}, 1.8 \mathrm{~m}$, and $1.9 \mathrm{~m}$ from the roadway ground; the specific settings are shown in Table 4.

3.1.1. Vertical Oxygen Outlet. In case A, the oxygen supply duct enters from the central position on the top of the roadway and goes down vertically along the wall on the heading face, as shown in Figure 4.

After adjusting the height of the oxygen supply duct outlet to $1.7 \mathrm{~m}, 1.8 \mathrm{~m}$, and $1.9 \mathrm{~m}$, the mesh was generated and then calculated by FLUENT, and the result is shown in Figure 6.

As can be seen from Figure 6, when the oxygen supply duct is vertically lowered from the top of the roadway, the oxygen mass fraction within the breathing zone $(1.2 \mathrm{~m}-1.6 \mathrm{~m})$ in the range of $1-5 \mathrm{~m}$ at the heading face is 0.246 , reaching the target level of $5 \%$ higher than the local oxygen mass fraction ( 0.242$)$. The oxygen concentration in other areas also increased by different degrees. The overall trend of oxygen concentration distribution is that, in the center of the roadway, it is relatively uniform and then decreases successively along the right side horizontally.

Horizontally, in the same height case, due to the effect of airflow and oxygen diffusion, oxygen gradually spread from the inlet of the exhausting duct which is $3 \mathrm{~m}$ away from the heading face at the lower left corner. Therefore, the average oxygen mass fraction in breathing zone at 2 meters behind the inlet of the exhausting duct ( 5 meters away from the heading face) is the highest. Vertically, from the perspective of the oxygen supply duct outlet height, when it is $1.7 \mathrm{~m}$ away from the ground (case 2.1), the relatively high oxygen concentration region in the breathing zone (yellow part in Figure 6) comes to the largest, and the oxygen supply effect is optimal. As the height of the oxygen supply duct outlet rises to $1.8 \mathrm{~m}$ and $1.9 \mathrm{~m}$, the area of relatively high oxygen concentration region gradually decreases, but the oxygen concentration of the breathing zone is basically guaranteed to reach the ideal level ( $5 \%$ higher than the local oxygen mass fraction). Reducing the oxygen outlet height from the ground may very likely increase the oxygenation effect, but being too close to the ground will hinder miners' operations. Therefore, in combination with various factors, the optimal height of the oxygen supply duct for vertical design is $1.7 \mathrm{~m}$ (case 2.1).

The highest oxygen concentration is reached at the bottom left corner and gradually decreases along the diagonal line, reaching the lowest at the top right area of the roadway. In addition to the exhausting duct inlet area, the oxygen concentration in the upper area of the roadway is higher than that in the bottom area. The overall oxygen mass fraction at the right side was lower than that at other locations. The lowest level of oxygen mass fraction is the place where the forcing duct outlet is, and the highest level is the place where the exhausting duct is. Oxygen accumulates at the inlet of the exhausting duct along with the airflow, which is also consistent with the movement of airflow driven by airflow ducts, as shown in Figure 7.

When fresh air flows out of the airflow duct, it is directed to the working surface with a gradually expanding free air current. Since the jet exit airflow speed is larger than the surrounding air, the surrounding air will be continuously drawn during the forward flow, and the air volume and the jet cross section in the jet fluid are continuously increased. When the jet section develops to a certain level, the jet fluid begins to evolve into the air surrounding the entrainment. When the airflow reaches the heading face, the continuity of the press-in airflow is affected by the wall and the airflow direction turns. Then the part of the wind flow is entrained by the jet, and a vortex is formed near the outlet of the forcing duct. Part of the airflow enters the coaction zone of the mixed ventilation airflow, which drives the oxygen from the jet to flow to the exhausting duct. 

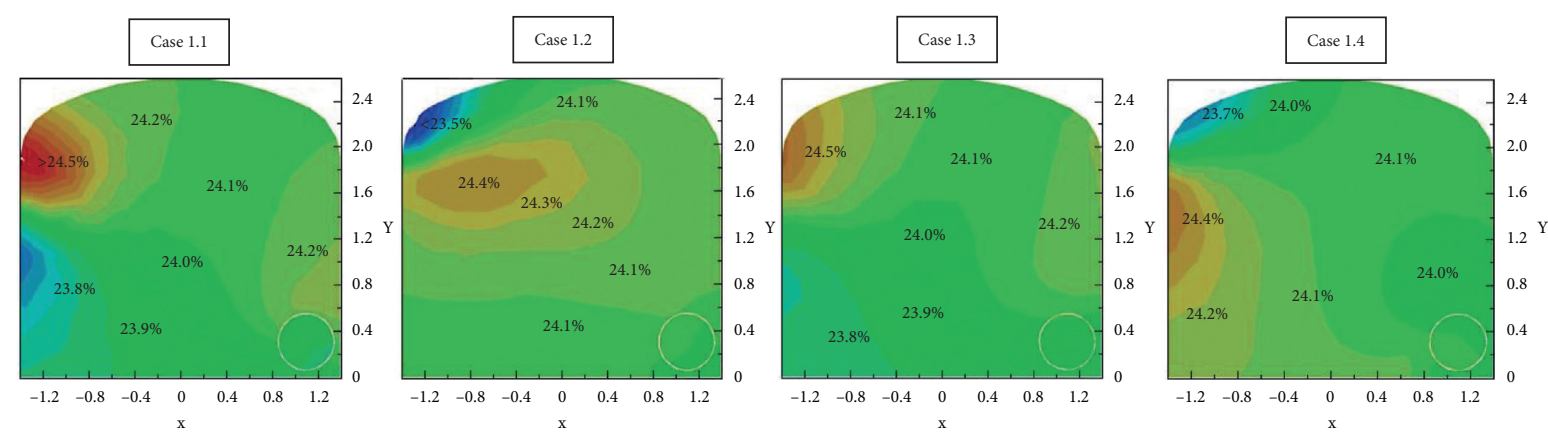

FIGURE 3: The comparison of oxygen mass fraction distribution of four cases.

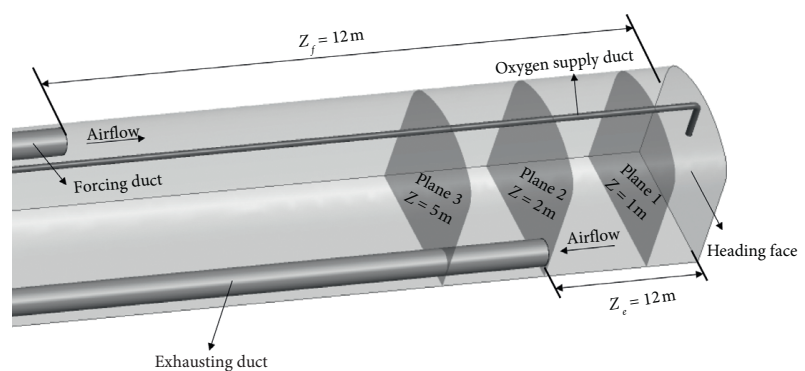

Figure 4: Geometry model of case A (note: $\mathrm{Z}$ is the distance between the plane and heading face).

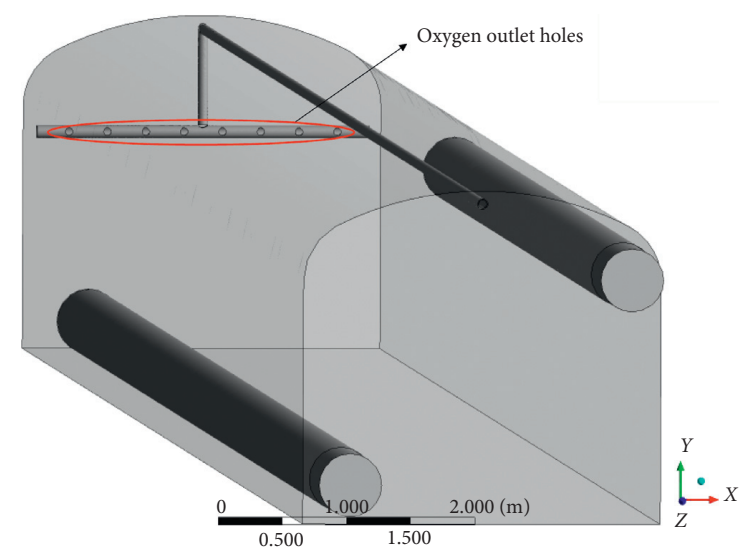

Figure 5: The profile of horizontal oxygen duct in case B.

3.1.2. Horizontal Oxygen Outlet. In case B, a $2.6 \mathrm{~m}$ horizontal duct with evenly distributed holes was added based on the vertical oxygen duct in the previous section (case A). The diameters of horizontal duct and holes are $0.05 \mathrm{~m}$ and $0.008 \mathrm{~m}$, respectively. The distance between two holes is $0.3 \mathrm{~m}$, as shown in Figure 5.

After adjusting the height of the holes center in horizontal duct to $1.7 \mathrm{~m}, 1.8 \mathrm{~m}$, and $1.9 \mathrm{~m}$, the mesh was generated and then calculated by FLUENT, and the result is shown in Figure 8.

As can be seen from Figure 8, as a complete unit, the overall distribution of oxygen in this part (case B) is similar to that of case $\mathrm{A}$, but the oxygen mass fraction is significantly higher than that of B. Except the upper part of the forcing duct, which is also the right top of the roadway, the oxygen mass fraction within the range of $1 \mathrm{~m}-5 \mathrm{~m}$ from the heading face is higher than 0.242 , achieving the target effect of increasing oxygen perfectly ( $5 \%$ higher than the local oxygen mass fraction). The highest oxygen concentration is reached at the bottom left corner and gradually decreases along the diagonal line, reaching the lowest at the top right part of the roadway.

However, conversely, the oxygen concentration in the upper part of the roadway is lower than that in the bottom area. From the perspective of the oxygen supply duct outlet height, when it is $1.9 \mathrm{~m}$ away from the ground (case 2.6), the relatively high oxygen concentration area in the breathing zone comes to the largest, and the oxygen supply effect is optimal. As the height of the oxygen supply duct outlet descends to $1.8 \mathrm{~m}$ and $1.7 \mathrm{~m}$, the area of relatively high oxygen concentration area decreases. Also, the height of 1.9 meters will not affect the operations of mines, so it is the optimal height of the oxygen supply duct for horizontal design (case 2.6).

3.1.3. Horizontal versus Vertical. In order to compare the oxygen-increasing effects of the two designs more intuitively, the average oxygen mass fraction of the breathing zone was calculated. The results are shown in Table 5.

For the oxygen-increasing effects as a whole, the horizontal oxygen outlet is better than vertical oxygen outlet. The average oxygen mass fraction in the breathing zone of case $\mathrm{A}$ was 0.006 higher than that of case B. Although 0.002 may seem small, this is a significant difference in oxygen-increasing effects. For the feasibility index of ventilation and aeration system design of plateau metal mine drivage, not only technical index but also economic index should be considered. It is a complex system with multiple links and factors, and it is difficult to comprehensively evaluate from a single aspect. Therefore, although the oxygen-increasing effect of the vertical design duct is less than that of the horizontal one, the overall oxygen-increasing index can also be achieved. Moreover, the design of vertical duct is simple, the layout is convenient, and its economic cost can be reduced. So, these two methods can be applied for different needs. 
TABle 4: Specific settings in case A and case B.

\begin{tabular}{llcc}
\hline & & Oxygen outlet direction & Height of oxygen duct outlet $(\mathrm{m})$ \\
\hline & Case 2.1 & Vertical & 1.70 \\
Case A & Case 2.2 & Vertical & 1.80 \\
& Case 2.3 & Vertical & 1.90 \\
& Case 2.4 & Horizontal & 1.70 \\
Case B & Case 2.5 & Horizontal & 1.80 \\
& Case 2.6 & Horizontal & 1.90 \\
\hline
\end{tabular}

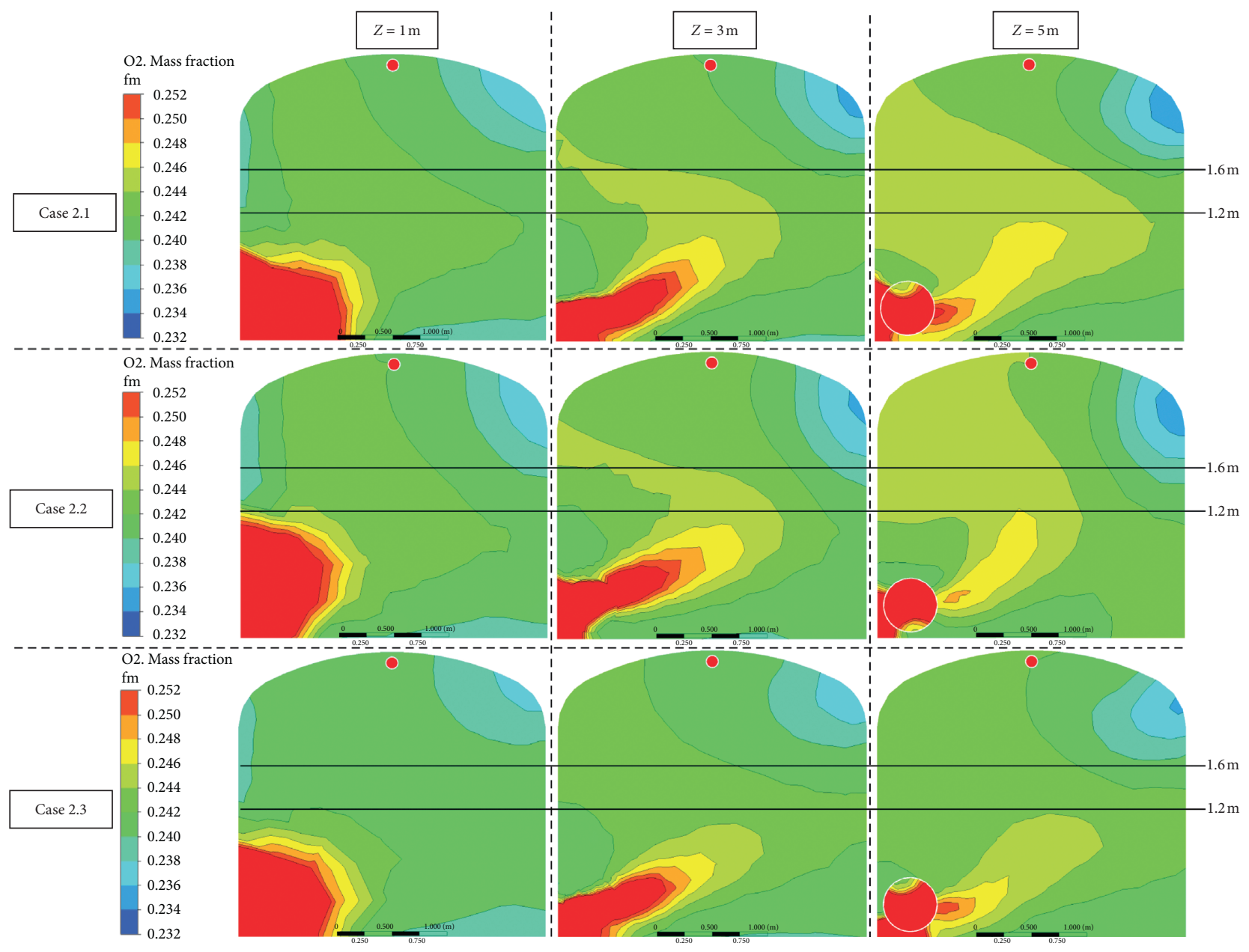

FIgURE 6: The oxygen mass fraction distribution in case A.

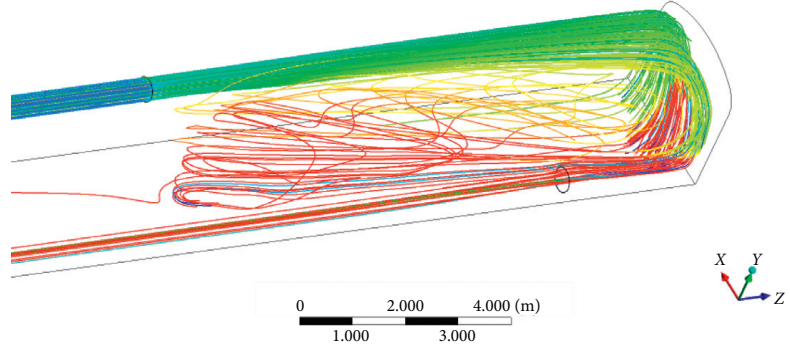

Figure 7: The airflow and oxygen velocity streamline in case 2.1. 


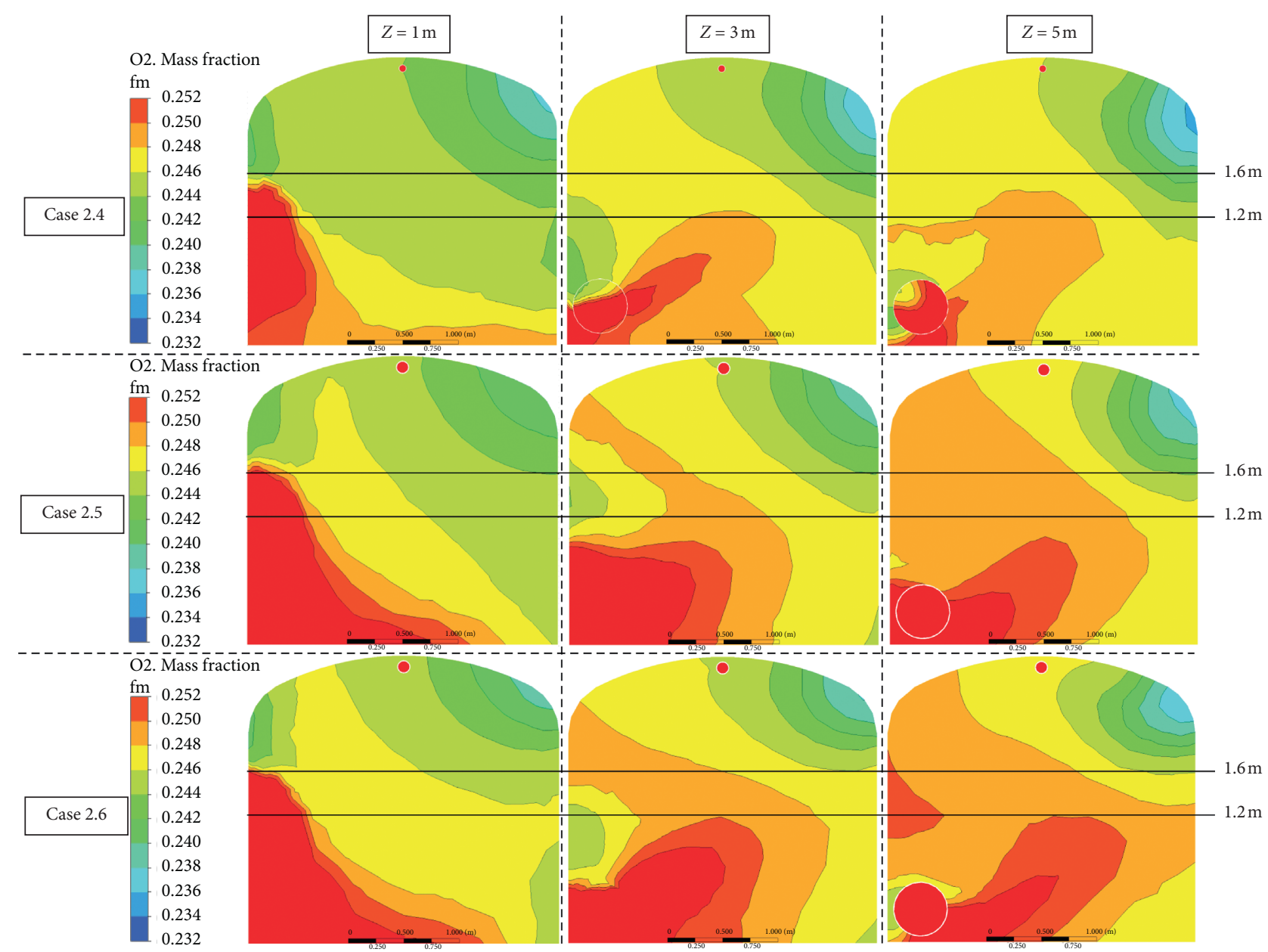

Figure 8: The oxygen mass fraction distribution in case B.

TABLE 5: Average oxygen mass fraction in the breathing zone of the two designs.

\begin{tabular}{lllll}
\hline & & $Z=1$ & $Z=3$ & $Z=5$ \\
\hline \multirow{2}{*}{ Oxygen mass fraction } & Case 2.1 & 0.242 & 0.243 & 0.245 \\
& Case 2.6 & 0.247 & 0.249 & 0.241 \\
\hline
\end{tabular}

\subsection{Scenario 2: Other Designs}

3.2.1. Duct with Holes. Previous simulations have shown that a few holes in the oxygen supply duct at the heading face make the oxygen diffuse better. So, based on case A (case 2.1), 5 holes with a radius of $0.03 \mathrm{~m}$ were evenly distributed in the vertical oxygen duct (case C), as shown in Figure 9.

From Figure 9, the oxygen mass fraction distribution pattern is similar to case A. But, clearly, the overall oxygen mass fraction has increased significantly. Even the lowest oxygen mass fraction in the heading face exceeded the target value 0.242 . The oxygen is relatively evenly distributed in the breathing zone. In addition, the high oxygen concentration is in the breathing zone. Therefore, it is possible to reduce the amount of oxygen supply by an appropriate amount to save economic costs.
3.2.2. Horizontal Duct with Higher Exhausting Duct. As can be seen from previous simulations, due to the airflow effect, oxygen always tends to concentrate around the inlet of the exhausting duct, resulting in a certain amount of oxygen waste. To solve this problem, two geometry models were built, as shown in Figures 10 and 11.

Case $\mathrm{D}$ is based on case B; the only difference is that the exhausting duct is not put on the ground but is hung $1 \mathrm{~m}$ above the ground, as shown in Figure 10. Because of the airflow effect, when $Z=1$, the cross section is near to the oxygen outlet; the oxygen still concentrated in the exhausting duct inlet direction. But when $Z=3$, the high oxygen concentration region moves down to the lower left corner because oxygen has a higher molecular weight than air. When $Z=5$, oxygen distributes better. However, the oxygen concentration distribution of the breathing zone is not as uniform as expected. Compared with case C, its oxygen-increasing effect and oxygen distribution pattern are not ideal.

Also, a method that sets the oxygen duct outlet near the outlet of the forcing duct direction was tried, and the oxygen outlet direction is opposite to the airflow direction, as shown in Figure 11, case E. 


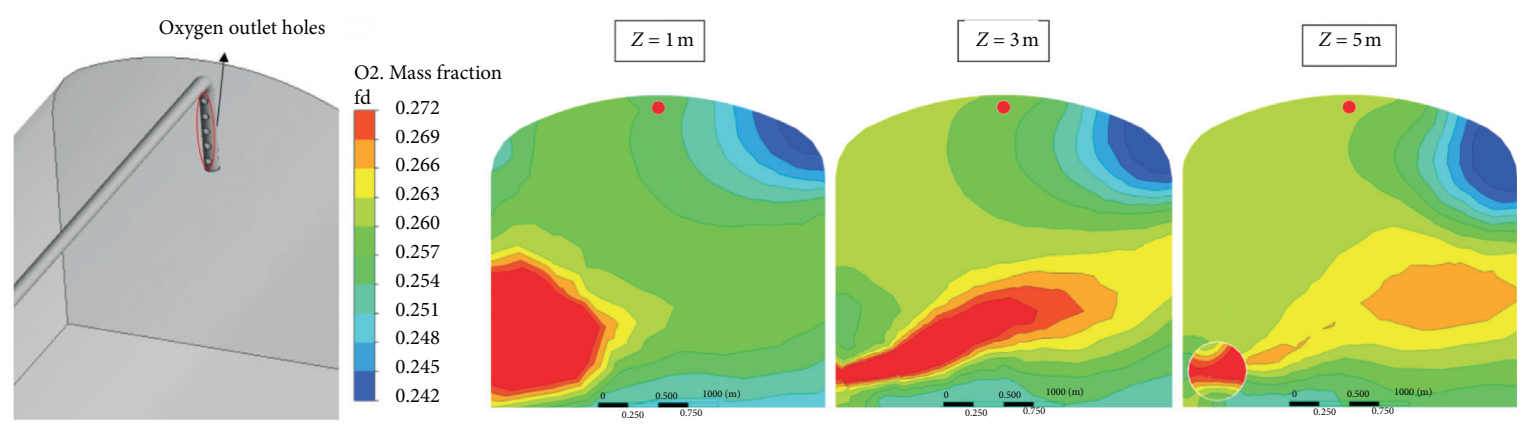

Figure 9: The profile of oxygen duct holes in case C.
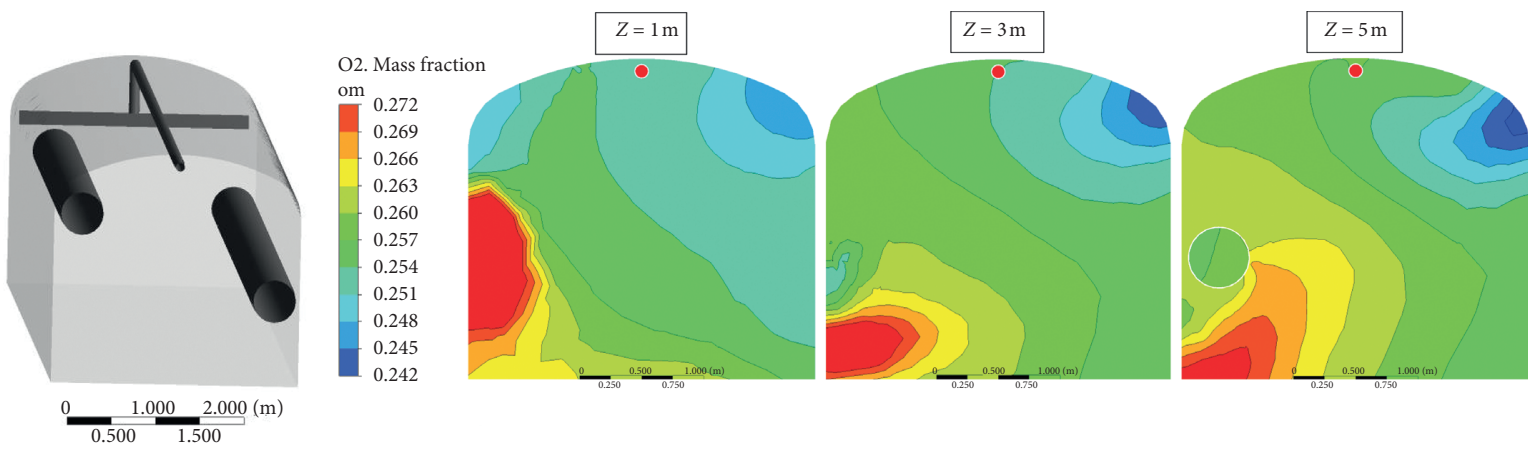

Figure 10: The profile of oxygen duct holes in case D.
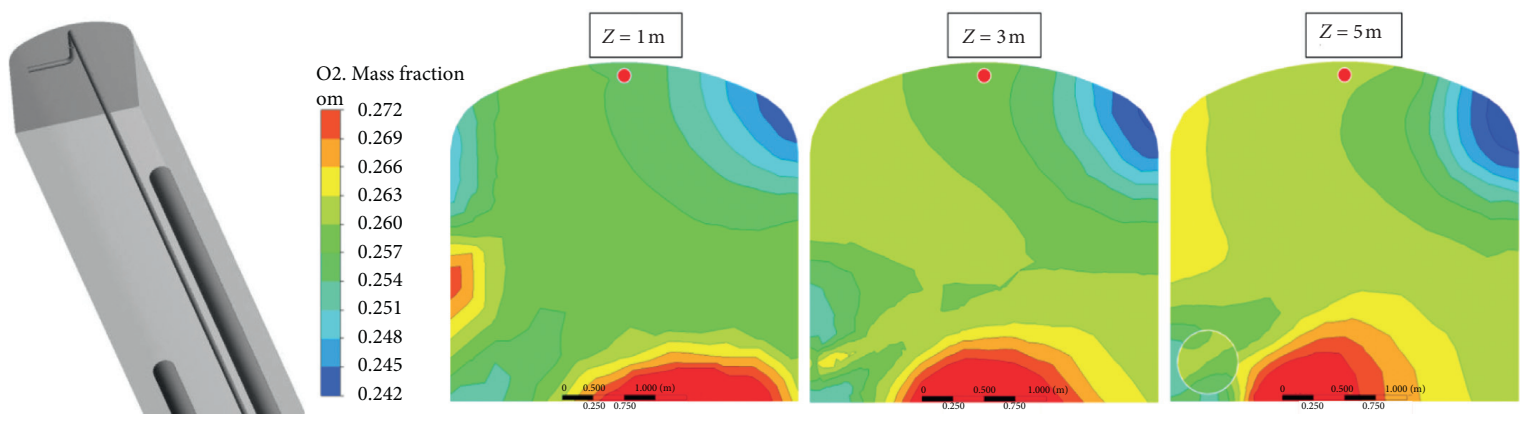

Figure 11: The profile of oxygen duct holes in case E.

The result shows that the overall oxygen mass fraction is higher than 0.242 , and the oxygen mass fraction in the breathing zone is evenly distributed, reaching 0.263 . Different from other cases, the highest oxygen mass fraction region is at the middle bottom of the roadway; it does not achieve the desired results as well. The reason is that the speed of the airflow is much higher than the speed of the oxygen outflow, and the forcing duct is pulled a little bit close to the heading face, so the oxygen is taken away after it has not been dispersed.

\section{Conclusions}

In order to solve the problem of lack of oxygen in roadway driving on the plateau, the mixed ventilation with a forcing duct $12 \mathrm{~m}$ away and an exhausting duct $3 \mathrm{~m}$ away from the heading face was selected as the optimal ventilation system. Then a series of computational studies have been conducted to evaluate the oxygen mass fraction distribution and oxygen-increasing effect with different oxygen supply duct designs in the blind heading face of a plateau metal mine in western China. Two different scenarios with five cases were created in various oxygen duct designs.

In scenario 1 , case A and case B were generated. The lowest oxygen mass fraction is the place where the forcing duct outlet is, and the highest is concentrated around the exhausting duct in the left corner. Oxygen diffuses along the diagonal from the left corner, which relates to the airflow. The best dispersion effect was found 5 meters away from the heading face. Both case A and case B achieved greatly the target of increasing oxygen mass fraction $5 \%$ higher than the local (0.242). But, in general, the result of case B is better 
than case $\mathrm{A}$; the average oxygen mass fraction in the breathing zone of case A was significantly higher than that of case $\mathrm{B}$, although case $\mathrm{B}$ is more economical and convenient.

In scenario 2, three not commonly used design models have been built and simulated. Among these cases, case C presents the best oxygen supply effect. The oxygen mass fraction in the breathing zone is high and evenly distributed. Also, case C is simple in design, low in cost, and easy to use. The results of other designs in this scenario are not as good as expected. So, considering all the factors, case $\mathrm{C}$ is the most suitable design in actual application in plateau metal mines.

\section{Data Availability}

The oxygen mass fraction data used to support the findings of this study are included within the article.

\section{Conflicts of Interest}

The authors declare that there are no conflicts of interest regarding the publication of this paper.

\section{Acknowledgments}

This research is supported by the National Key R\&D Program of China (Project no. 2018YFC0808404) and Fundamental Research Funds for Central Universities of Central South University (Project no. 2019zzts991).

\section{References}

[1] C. W. Wang, L. X. Niuand, and S. X. Fu, "Distribution research on non-ferrous metal exploration bases in Xinjiang province," Mining R\&D, vol. 35, no. 8, pp. 102-106, 2015.

[2] Y.-X. Gao, P. Li, C.-H. Jiang et al., "Psychological and cognitive impairment of long-term migrators to high altitudes and the relationship to physiological and biochemical changes," European Journal of Neurology, vol. 22, no. 10, pp. 1363-1369, 2015.

[3] E. C. Heinrich, M. A. Djokic, D. Gilbertson et al., "Cognitive function and mood at high altitude following acclimatization and use of supplemental oxygen and adaptive servo ventilation sleep treatments," PloS One, vol. 14, no. 6, 2019.

[4] J. S. Lawley, N. Alperin, A. M. Bagci et al., "Normobaric hypoxia and symptoms of acute mountain sickness: elevated brain volume and intracranial hypertension," Annals of Neurology, vol. 75, no. 6, pp. 890-898, 2014.

[5] D. R. Woods, J. P. O'Hara, C. J. Boos et al., "Markers of physiological stress during exercise under conditions of normoxia, normobaric hypoxia, hypobaric hypoxia, and genuine high altitude," European Journal of Applied Physiology, vol. 117, no. 5, pp. 893-900, 2017.

[6] S. Bian, J. Jin, Q. Li et al., "Hemodynamic characteristics of high-altitude headache following acute high-altitude exposure at $3700 \mathrm{~m}$ in young Chinese men," The Journal of Headache and Pain, vol. 16, no. 1, pp. 1-13, 2015.

[7] C. Guo, J. Xu, M. Wang, T. Yan, L. Yang, and Z. Sun, "Study on oxygen supply standard for physical health of construction personnel of high-altitude tunnels," International Journal of Environmental Research and Public Health, vol. 13, no. 1, 2016.

[8] C. K. Jundika, P. S. Agus, and S. M. Arun, "Simulation of a novel intermittent ventilation system for underground mines," Tunneling and Underground Space Technology, vol. 42, pp. 206-215, 2014.

[9] M. T. Parra, J. M. Villafruela, F. Castro, and C. Méndez, "Numerical and experimental analysis of different ventilation systems in deep mines," Building and Environment, vol. 41, no. 2, pp. 87-93, 2006.

[10] P. S. Agus, B. Erik, C. L. Hung, and A. S. Mujumdar, "Some approaches to improve ventilation system in underground coal mines environment-a computational fluid dynamic study," Tunneling and Underground Space Technology, vol. 34, pp. 82-95, 2013.

[11] J. Park, S. Park, and D.-K. Lee, "CFD modeling of ventilation ducts for improvement of air quality in closed mines," Geosystem Engineering, vol. 19, no. 4, pp. 177-187, 2016.

[12] P. Chang, G. Xu, F. Zhou, B. Mullins, S. Abishek, and D. Chalmers, "Minimizing DPM pollution in an underground mine by optimizing auxiliary ventilation systems using CFD," Tunnelling and Underground Space Technology, vol. 87, pp. 112-121, 2019.

[13] V.-D. Nguyen, W.-H. Heo, R. Kubuya, and C.-W. Lee, "Pressurization ventilation technique for controlling gas leakage and dispersion at backfilled working faces in largeopening underground mines: CFD analysis and experimental tests," Sustainability, vol. 11, no. 12, p. 3313, 2019.

[14] Z. Wang, S. Li, T. Ren, J. Wu, H. Lin, and H. Shuang, "Respirable dust pollution characteristics within an underground heading face driven with continuous miner - a CFD modelling approach," Journal of Cleaner Production, vol. 217, pp. 267-283, 2019.

[15] W. Wang, C. Zhang, W. Yang et al., "In situ measurements and CFD numerical simulations of thermal environment in blind headings of underground mines," Processes, vol. 7, no. 5, p. 313, 2019.

[16] I. S. Lowndes, A. J. Crossley, and Z. Y. Yang, "The ventilation and climate modelling of rapid development tunnel drivages," Tunneling and Underground Space Technology, vol. 19, no. 2, pp. 139-150, 2004.

[17] J. Gao, K. Uchino, and M. Inoue, "Simulation of thermal environmental conditions in heading face with forcing auxiliary ventilation. Control of thermal environmental conditions in locally ventilated working place. 1st report," Shigento-Sozai, vol. 118, no. 1, pp. 9-15, 2002.

[18] H. Zhong, N. L. Hu, G. Q. Li, and J. Hou, "On the oxygenintensifying ventilation technology for plateau mine tunneling via the application of the software Fluent," Journal of Safety and Environment, vol. 17, no. 1, pp. 81-85, 2017.

[19] X. D. Wang, Research on Ventilation System of Metal Mine at High Altitude, C\&EES, Mining Engineering, University of Science \& Technology, Beijing, China, Ph.D. dissertation, 2014.

[20] Y. Wang, P. Suraneni, L. Yu, W. Q. Xie, and Y. Dai, "Experimental methods to determine the feasibility of steel slags as supplementary cementitious materials," Construction and Building Materials, vol. 204, pp. 458-467, 2019.

[21] T. Yan, M. N. Wang, C. Guo, H. B. Chen, and W. Q. Xie, "Key techniques for diffused oxygen supply of an extra- long highway tunnel in a high-altitude area," Modern Tunneling Technology, vol. 52, no. 2, pp. 180-185, 2015.

[22] Z. Z. Duan, ANSYS FLUENT Fluid Analysis and Engineering Examples, p. 23, Publishing House of Electronics Industry, Beijing, China, 2015.

[23] C. Wu, Mine Ventilation and Air Conditioning, pp. 144-152, Central South University Press, Hunan, China, 2008.

[24] Y. S. Liu, H. S. Cui, W. H. Liu, J. X. Feng, and Q. X. Yu, "Study on technology of oxygen supply in tunnel development in high attitude area," Mining and Metallurgy, vol. 14, no. 1, pp. 5-12, 2005. 